\title{
Plane-interface-induced lignin-based nanosheets and its reinforcing effect on styrene-butadiene rubber
}

\author{
C. Jiang, H. He*, P. Yu, D. K. Wang, L. Zhou, D. M. Jia \\ Department of Polymer Materials and Engineering, South China University of Technology, Guangzhou 510640, People's \\ Republic of China
}

Received 12 March 2014; accepted in revised form 27 April 2014

\begin{abstract}
Lignin was viewed as a spherical microgel in aqueous alkali. While spread out in a monolayer or adsorbed on a surface, lignin was made up of flexible, disk-like molecules with approximately the same thickness of $2 \mathrm{~nm}$. According to this principle, we employed the lamina of montmorillonite (MMT) as a plane template to anchor cationic lignin (CL) on its two sides, resulting in the formation of CL-MMT hybrid materials (CLM). The isotherm adsorption behavior and structure characteristics of CLM were studied. The results showed that CLM was individually dispersed nanosheets with a thickness of about $5 \mathrm{~nm}$ when the mass ratio of CL to MMT is more than 2:1 and prepared at acidic or neutral $\mathrm{pH}$. Compared to the cocoagulation of lignin and styrene-butadiene rubber (SBR), CLM obviously accelerated the coagulation rate, due to the reduction of surface activity of CL restricted by MMT. The nanoscale dispersion of CLM in SBR matrix significantly improved the tensile strength of CLM/SBR nanocomposites to $14.1 \mathrm{MPa}$ by adding only $10 \mathrm{phr}$ CLM and cardanol glycidyl ether (CGE) as compatibilizer. Dynamic mechanical analysis (DMA) showed that the glass transition temperature of SBR/CLM nanocomposites decreased with increasing CLM loading. Correspondingly, a special interfacial structure was proposed.
\end{abstract}

Keywords: nanomaterials, lignin, montmorillonite, complete exfoliation, nanosheets

\section{Introduction}

Lignin is the most abundant renewable aromatic biopolymer on earth, widely existing in the cell walls of all high-level plants. It mainly consists of three phenylpropanoid units such as p-hydroxyphenyl, guaiacyl and syringyl, which are attached to one another by a series of characteristic linkages ( $\beta-\mathrm{O}-4$, $\beta-5, \beta-\beta$, etc.) $[1,2]$. Traditionally, lignin has been viewed as a waste material or a low value byproduct of pulp and paper industry, primarily used as fuel due to its high energy content. Only a small proportion is utilized for high value-added products [3]. As emerging biorefinery industries continue to evolve, lignin utilization will become significantly more important. Unfortunately, the heterogeneity of chemical structure of lignin seems to be a persistent challenge to fully realize the potential of lignin [4], although the complex molecule structure and various chemical functional groups (ether linkages, aliphatic and aromatic hydroxyl groups), render lignin lots of functionalities such as hydrophobicity, reinforcing effect, biodegradability and UV-adsorption $[5,6]$. To address this issue and maximize the value of ligninbased products, it will be an effective strategy to develop nanostructured lignin or lignin-based nanomaterials.

Nanostructured materials have attracted a great deal of attentions in the past decades, owing to their fascinating properties and potential applications in polymer composites [7], electrochemical energy storage and conversion [8], catalysis [9], sensor [10] and drug delivery [11]. Therefore, it will be a promising way to convert amorphous and strongly self-aggregated lignin into some nanostructured materials,

\footnotetext{
${ }^{*}$ Corresponding author, e-mail: pshuihe@scut.edu.cn

(C) BME-PT
} 
giving us more chances to exploit novel functional applications based on lignin. Actually, earlier studies have demonstrated that lignin dissolved in some solvents possesses a nanostructure, but the shape and size intensively depend on the chosen solvent and analytical methods [12]. It is rather difficult to get a general picture of the exact shape and the actual size of an isolated lignin particle. In addition, there are strong hydrogen bonding interactions [13, 14] and $\pi-\pi$ interactions [15] in lignin molecules, thereby resulting in serious thermally irreversible aggregation when lignin is recovered from solutions. As a consequence, it is rather difficult to obtain nanostructured lignin. To date, just few literatures on nanostructured lignin or lignin-based nanomaterials were reported. For example, Hector M Caicedo and coworkers adopted alumina membranes as a sacrificial template to prepare lignin-based nanotubes, in which lignin was transformed into nanotubes with a wall thickness of approximately $15 \mathrm{~nm}$ or nanowires with a nominal diameter of $200 \mathrm{~nm}$ [16]. Moreover, Jonathan Spender et al. [17] reported an extended icesegregation-induced self-assembly methodology to produce carbon nanofibers (CNFs) with a diameter of less than $100 \mathrm{~nm}$. Besides above-mentioned onedimensional (1D) lignin-based nanotubes and nanofibers, zero-dimensional (0D) lignin nanoparticles or lignin-based carbon nanoparticles are also successfully prepared via kinds of strategies [18-20]. However, to our knowledge, there is no report on successful synthesis of two-dimensional (2D) lignin nanosheets so far. In this paper, we present a novel approach to prepare 2D lignin-based nanosheets by using montmorillonite (MMT) as a plane template. Montmorillonite, a naturally occurring layered clay, consists of stacks of platelets obtained by combining two tetrahedral silica layers with $\mathrm{Mg}$ or $\mathrm{Al}$ to form an octahedral metal oxide structure [21]. Each platelet (about $0.96 \mathrm{~nm}$ thick) is separated from the next by interlayer cations $\left(\mathrm{Na}^{+}, \mathrm{K}^{+}, \mathrm{Ca}^{2+} \ldots\right)$, which can be easily replaced by other organic cations, thereby providing an essential way to introduce different functional groups so that design materials with required structure and performance [22-26]. Generally, MMT is used as a reinforcing filler to promote the mechanical, thermal and barrier properties of polymer, which essentially depend on the degree of interaction or exfoliation of MMT within polymer matrix $[27,28]$. However, it is very difficult to obtain completely exfoliated MMT via a simple procedure. Especially in nonpolar polymer matrix, very few efforts have been made to obtain highly exfoliated MMT [29].

Commonly, lignin in solution is assumed to be an approximately spherical microgel between that of an Einstein sphere and a linear nonfree-draining random coil with different hydrodynamic sizes from several nanometers to several hundred nanometers [13]. While spread out in a monolayer or adsorbed onto a surface, lignin is envisaged as being made up of flexible, disk-like molecules having various shapes and sizes but all with approximately the same thickness of $2 \mathrm{~nm}$ [30]. Herein, because of the huge aspect ratio of MMT platelets, we employed MMT as a plane template and CL as adsorbate to exchange the layer cations of MMT. To our surprise, MMT was completely exfoliated and a large amount of CL as disk-like spots with a thickness of about $2 \mathrm{~nm}$ was anchored on the surface of MMT platelets, resulting in the formation of individually dispersed CL-decorated MMT (CLM) nanosheets with different surface charge status in aqueous solution. We successfully fabricated 2D lignin-based nanosheets for the first time by the template of MMT, thus providing a versatile and promising way to prepare high valueadded lignin products with potential applications in reinforcement for polymer as nano-filler via latex compounding, universal building blocks for UV absorption through simple drop-coating method, etc. To elucidate one of its applications, we incorporated the resulting CLM into SBR via latex co-coagulating method. The morphology, mechanical and dynamic mechanical properties of the CLM/SBR composites and the interface structure between CLM and SBR matrix were investigated in detail.

\section{Materials and methods 2.1. Materials}

Lignin (industrial sulfate lignin), with an average molecular weight $\left(M_{\mathrm{W}}\right)$ of 3801 and polydispersity index of 2.15, was purchased from Tralin Paper Co., Ltd. (Shandong, China). $\mathrm{Na}^{+}-\mathrm{MMT}$, with a cationic exchange capacity of $100 \mathrm{meq} / 100 \mathrm{~g}$, was supplied by Nanhai Inorganic Factory (Guangdong, China). Sodium hydroxide $(\mathrm{NaOH})$, hydrochloric acid $(\mathrm{HCl})$ and sulfuric acid $\left(\mathrm{H}_{2} \mathrm{SO}_{4}\right)$ were analytical grade, purchased from Guangzhou Chemical Reagent Factory, China. The reagents for synthesis of CL including epichlorohydrin (98\%) and trimethylamine water solution (33\%) were obtained from Lingfeng Chemi- 
cal Reagent (Shanghai, China) and used as received. Deionized water (resistivity $>18 \mathrm{M} \Omega \cdot \mathrm{cm}$ ) was obtained from a Millipore water purification system. SBR latex (intex 132, solid content $65 \mathrm{wt} \%$ ) was purchased from Shanghai Nessen international Trading Co., Ltd. Cardanol glycidyl ether (CGE) was kindly provided by Shanghai Meidong biological material co., Ltd.. All the rubber ingredients were industrial grade and used as received.

\subsection{Synthesis of cationic lignin}

Prior to use, lignin was purified by a repetitive alkalidissolving-acid-precipitating method as previously described [31]. Subsequently, CL was synthesized according to the previous procedure $[32,33]$. In a typical experiment, trimethylamine $(60 \mathrm{mmol})$ was added into equimolar $\mathrm{HCl}$ solution to convert to a salt form, then dropwise added epichlorohydrin (50 mmol) and reacted at $52^{\circ} \mathrm{C}$ for $4 \mathrm{~h}$ to obtain glycidyltrimethylammonium chloride. After that, lignin $(10 \mathrm{~g})$ was dissolved in $100 \mathrm{~mL}$ of $1 \mathrm{M} \mathrm{NaOH}$ solution, and the pre-synthesized glycidyltrimethylammonium chloride was added to the lignin solution. The reaction mixture was stirred at $52^{\circ} \mathrm{C}$ for $19 \mathrm{~h}$. Finally, the resultant CL was recovered by precipitation in 2 L ethanol solution (95\%) and washed with diethyl ether, followed by drying in a vacuum oven at $50^{\circ} \mathrm{C}$ for $24 \mathrm{~h}$. By employing a colloid titration method described by Ueno and Kina [34], the charge density of $\mathrm{CL}$ at $\mathrm{pH}=2$, which can be used for analyzing the mechanism of ion-exchange reaction, was measured to be $1.03 \mathrm{meq} / \mathrm{g}$ CL.

\subsection{Synthesis of CLM hybrid materials}

CL solutions containing $0.05,0.1,0.2$ and $0.4 \mathrm{~g}$ of $\mathrm{CL}$ in $25 \mathrm{~mL}$ deionized water were slowly added into a $2 \%$ MMT suspension $\left(0.5 \mathrm{~g}\right.$ of $\mathrm{Na}^{+}-\mathrm{MMT}$ in $25 \mathrm{~mL}$ of deionized water) to obtain hybrid materials with initial CL-MMT mass ratios of 0.1:1, 0.2:1, 0.4:1 and $0.8: 1$, respectively. For the preparation of CLM with CL-MMT mass ratio of 2:1, 4:1, 6:1 and 8:1, CL solutions with $1 \mathrm{~g}$ of CL in $125 \mathrm{~mL}, 2,3$ and $4 \mathrm{~g}$ in $250 \mathrm{~mL}$ respectively, were mixed with the MMT suspension. In order to investigate the effect of $\mathrm{pH}$ on the adsorption of CL to MMT, three groups of CL-MMT solutions with all CL-MMT mass ratios were prepared in total. The $\mathrm{pH}$ of the three groups was adjusted to 12,7 and 3 by adding a few drops of $0.1,0.01$ or $0.001 \mathrm{~N} \mathrm{HCl} / \mathrm{NaOH}$ solutions, respectively. Subsequently, the CL-MMT solutions were stirring at $50^{\circ} \mathrm{C}$ for $48 \mathrm{~h}$. The resulting solutions were filtrated through a nylon membrane $(0.22 \mu \mathrm{m})$ and washed with deionized water of corresponding $\mathrm{pH}$. The filtrate was collected for determination of the adsorbed amount of CL on MMT. The purified supernatants, namely CLM hybrid materials, were centrifuged at $4000 \mathrm{rpm}$ to exclude the un-exfoliated and un-suspended part, then vacuum dried at $50^{\circ} \mathrm{C}$ and ground to powder or redispersed in deionized water of corresponding $\mathrm{pH}$ for further analysis.

\subsection{Determination of adsorbed amount of CL on MMT}

The adsorbed amount of CL was estimated from the difference in the initial CL mass and the mass in the filtrate. The amount of CL in filtrate was determined with a UV756CRT UV-vis spectrophotometer (Shanghai Youke Instrument CO. Ltd., China) using a calibration curve, which was obtained from measurements of five samples of CL diluted in $0.01 \mathrm{M}$ $\mathrm{HCl}$ to different concentrations at $277 \mathrm{~nm}$. The absorption coefficient for CL was determined to be $13.47 \mathrm{~L} \cdot \mathrm{g}^{-1} \cdot \mathrm{cm}^{-1}$.

\subsection{Preparation of CLM/SBR composites}

SBR latex was first diluted with deionized water to a solid content of about $10 \mathrm{wt} \%$ and then adjusted the $\mathrm{pH}$ to 7. A desired amount of CLM suspensions with $\mathrm{pH}$ of 7 was added into SBR latex and the mixture subsequently was coagulated by adding $\mathrm{CaCl}_{2}$ ( $2 \mathrm{wt} \%$ ). The co-coagulated compounds were washed with deionized water and vacuum dried over night at $50^{\circ} \mathrm{C}$. Then the dried compounds were compounded with rubber ingredients with a two-roll mill and subjected to compression at $150^{\circ} \mathrm{C}$ for the optimum curing time determined by the U-CAN UR2030 vulcameter. The composite that contained $2 \mathrm{phr}$ CLM was abbreviated as S-CLM-2. The meanings of other codes were deduced by analogy. The formulation of the composite is listed as follow, SBR 100 phr; zinc oxide 5 phr; stearic acid 1 phr; N-tertbutyl-2-benzothiazole sulfonamide $1 \mathrm{phr}$; dibenzothiazole disulfide $1.5 \mathrm{phr}$; sulfur $1.5 \mathrm{phr}$. In addition, 2 phr CGE was used as compatibilizer. Note that phr refers to parts per hundred of rubber.

\subsection{Characterizations}

Zeta potential and dynamic light scattering (DLS) were performed on a 90 Plus Particle Size Analyzer (Brookhaven Inst., Huntsville, NY, USA). Sample 
solution was diluted to the appropriate concentration with deionized water of corresponding $\mathrm{pH}$. For DLS, each analysis lasted for $180 \mathrm{~s}$ and was performed at $25^{\circ} \mathrm{C}$ with angle detection of $90^{\circ}$. Zeta potential of CLM and CL was determined by dipping a palladium electrode in sample solution. All the measurements were repeated 3 times and the average value was reported.

$\mathrm{X}$-ray diffraction (XRD) experiments were conducted at ambient temperature on a Rigaku Dmax/III diffractometer (Rigaku Corporation,Tokyo, Japan) using a $\mathrm{Cu} \mathrm{K \alpha}$ radiation $(\lambda=1.54 \AA)$. The generator was operated at $40 \mathrm{kV}$ and $30 \mathrm{~mA}$. The samples were scanned from 2 to $10^{\circ}$, with a step length of $0.02^{\circ}$. The microstructure and morphology of CLM, CL and SBR/CLM composites were visualized by a Hitachi H-7650 transmission electron microscope (TEM) at an accelerating voltage of $80 \mathrm{kV}$. The samples for TEM measurement were prepared by dropping sample solution or by ultramicrotome technology on $\mathrm{Cu}$ grids of 200 meshes.

The surface characteristics of CLM and CL were studied on a Multimode Pico-Force Atomic Force Microscopy (AFM, Veeco Instruments Inc., Santa Barbara, CA). All images were obtained using the tapping mode in air at ambient temperature. Real time scanning was performed with scan rates around $1.0 \mathrm{~Hz}$, scan angle $0^{\circ}$, and tapping frequencies ranging from 270 to $320 \mathrm{kHz}$. The samples were prepared by depositing the suspensions on freshly-cleaved mica surface and drying at room temperature.

Glass transition temperatures of CL, lignin and CLM were measured by differential scanning calorimeter (DSC, TA Instruments Q2000) using 3-5 mg samples in aluminum pans at a heating rate of $10^{\circ} \mathrm{C} / \mathrm{min}$ from $30 \mathrm{C}$ to $250^{\circ} \mathrm{C}$.

Thermogravimetric analysis (TGA) was performed under nitrogen atmosphere with a TG 209 F1 (NETZSCH Company, Germany) at a heating rate of $10{ }^{\circ} \mathrm{C} / \mathrm{min}$.

Scanning electron micrographs (SEM) of the composites were taken with a Nova NanoSEM 430 instrument (FEI, Netherlands) at an acceleration voltage of $10 \mathrm{kV}$. The fracture surface was obtained by splitting bulk sample being quenched in liquid nitrogen. Before the observation, a thin gold was evaporated on the fractured surface.

Dynamic mechanical analysis (DMA) spectra of the samples were obtained by using a DMA 242D dynamic mechanical analyzer (NETZSCH Company, Germany). The specimens with the size of $30 \mathrm{~mm} \times 6 \mathrm{~mm} \times 2 \mathrm{~mm}$ were analyzed in tensile mode at a constant frequency of $1 \mathrm{~Hz}$, a strain of $0.5 \%$, and a temperature range from -100 to $100^{\circ} \mathrm{C}$ at a heating rate of $3^{\circ} \mathrm{C} / \mathrm{min}$.

Tensile tests were performed with U-CAN UT-2060 (Taiwan) instrument, according to ISO standard 372005 at $25^{\circ} \mathrm{C}$.

\section{Results and discussion}

A wealth of studies on adsorption of polymer by clay, including positively charged, negatively charged and neutral polymer, has revealed distinct adsorption processes for the three types of polymer [35]. Actually, as shown in Figure 1, the CL we synthesized is a zwitterionic polymer and simultaneously possesses quaternary ammonium cations and ionizable anionic groups such as carboxylic groups $\left(\mathrm{p} K_{\mathrm{COOH}}<4.75\right)$ and phenolic hydroxyls $\left(\mathrm{p} K_{\mathrm{OH}} \approx\right.$ 10.5-11) [36], conferring a special property of tunable charge status to $\mathrm{CL}$ by changing $\mathrm{pH}$. Considering that carboxylic groups and phenolic hydroxyls of $\mathrm{CL}$ are completely ionized at $\mathrm{pH}$ of 12 whereas phenolic hydroxyls are protonated at $\mathrm{pH}$ of 7 and only quaternary ammonium cations remain at $\mathrm{pH}$ of 3 , we prepared CLM hybrid materials at this three $\mathrm{pH}$ values to investigate the effect of $\mathrm{pH}$ on adsorption process and degree of exfoliation of MMT. It is worthy to note that the CLM are denoted with the initial CL-MMT ratio employed in their preparation; nevertheless, such a ratio does not indicate the final CL amount adsorbed on MMT.

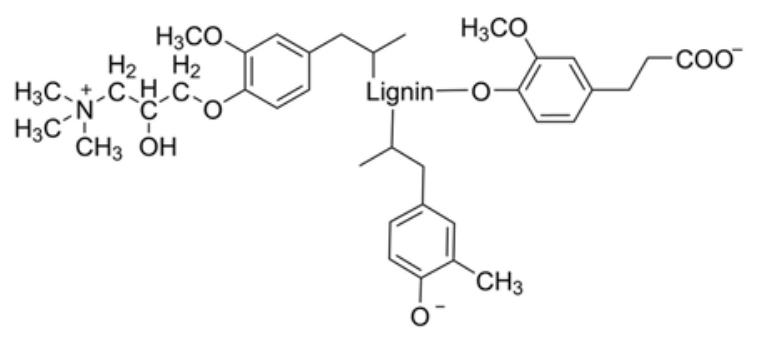

Figure 1. The possible chemical structure of CL

\subsection{Adsorption isotherms}

The adsorption isotherms at $50^{\circ} \mathrm{C}$ from CL solutions of three different $\mathrm{pH}$ onto MMT are presented in Figure 2. The data sets were fitted to the Langmuir Equation (1) using a nonlinear curve fitting program [37]: 


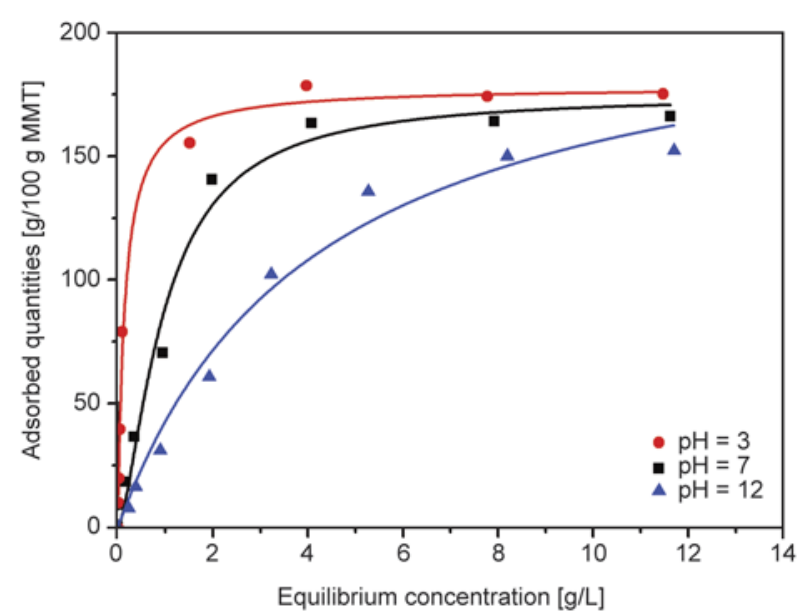

Figure 2. Adsorption isotherms of CL on MMT at different $\mathrm{pH}$, in an aqueous dispersion at $50^{\circ} \mathrm{C}$

$\Gamma=\frac{b Q C_{\mathrm{e}}}{1+b C_{\mathrm{e}}}$

where $\Gamma$ is the adsorbed amount of CL, $b$ is the affinity constant between CL and clay interaction sites, $C_{\mathrm{e}}$ is the equilibrium CL concentration and $Q$ is the maximum adsorbed amount. As shown in Figure 2, the good fitting curves of the three adsorption isotherms display distinct adsorption processes with different initial slopes, indicating the different affinities between CL and MMT. The affinity constant $b$ from the fitting data were $0.23 \pm 0.04 \mathrm{~g}^{-1} \cdot \mathrm{L}$ for $\mathrm{pH}=$ $12,1.04 \pm 0.25 \mathrm{~g}^{-1} \cdot \mathrm{L}$ for $\mathrm{pH}=7$ and $6.95 \pm 1.01 \mathrm{~g}^{-1} \cdot \mathrm{L}$ for $\mathrm{pH}=3$. The gradually increasing affinity constant from $\mathrm{pH}$ of 12 to 3 is indicative of the increase in the interactions between CL and MMT with decreasing $\mathrm{pH}$. It can be ascribed to the fact that the anionic groups of CL are protonated and the net charges change from negative to positive with decreasing $\mathrm{pH}$, providing intensively electrostatic interactions between CL and negatively charged MMT platelets, which can be confirmed by the zeta potential of CL in Table 1. For ionic species, $b$ can be related to the Gibbs free adsorption energy $\Delta G_{\text {ads }}$ through the relation $K=(b \rho / 4)^{2}$ where $\rho$ is the ratio of the solvent (water) density to its molecular weight, $\rho \approx$ $55.6 \mathrm{~mol} \cdot \mathrm{L}^{-1}$, as shown by Equation (2) [38]:

$\Delta G_{\text {ads }}=-R T \ln K$ where $R$ is the gas constant and $T$ is the adsorption temperature. Since the positive charge amount of CL was determined to be $1.03 \mathrm{meq} / \mathrm{g}$ CL by colloid titration method, the affinity constants between quaternary ammonium cations on $\mathrm{CL}$ and negatively charged sites in MMT at the three $\mathrm{pH}$ were still the above values by calculation. Consequently, the Gibbs free adsorption energies for quaternary ammonium cations of CL onto MMT at $\mathrm{pH}$ of 12,7 and 3 were $-43.34,-51.45$ and $-61.65 \mathrm{~kJ} \cdot \mathrm{mol}^{-1}$ respectively. Such a high Gibbs free adsorption energy at $\mathrm{pH}$ of 3 is comprehensible due to the strong coulombic interactions, whereas a relatively high Gibbs free adsorption energy at $\mathrm{pH}$ of 12 existing in an electrostatic repulsion system $\left(\zeta_{\mathrm{CL}}=-19.8 \pm 2.0 \mathrm{mV}\right.$ and $\zeta_{\mathrm{MMT}}=$ $-32.3 \pm 3.5 \mathrm{mV}$, Table 1) may be ascribed to other strong interactions between CL and MMT except coulombic interactions or other reasons, which will be further discussed in the following text.

Additionally, the maximum adsorbed amount of CL onto MMT at $\mathrm{pH}$ of 12, 7 and 3, are 152.1, 175.6 and $177.3 \mathrm{~g}$ per $100 \mathrm{~g}$ of MMT respectively, which are much more than the estimated maximum adsorbed amount of CL, $97.1 \mathrm{~g} / 100 \mathrm{~g}$ MMT. The excess of CL adsorbed onto MMT provides CLM hybrid materials with enough electrostatic repulsion force to sta-

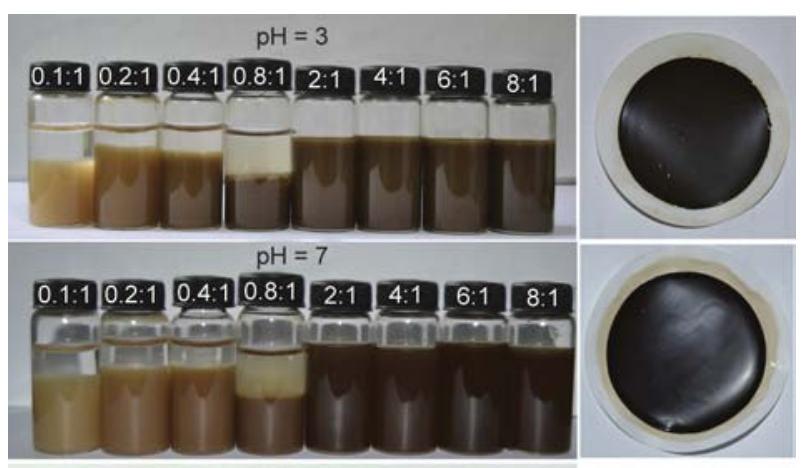

$\mathrm{pH}=12$

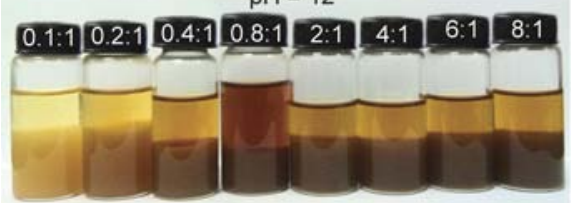

Figure 3. Digital photographs showing the suspensions of CLM hybrid materials in aqueous solutions at $\mathrm{pH}=3,7$ and 12 (left) and the corresponding CLM papers with mass ratio of 2:1 (right)

Table 1. The zeta potential and hydrodynamic diameters by DLS of MMT, CL and CLM at pH of 3, 7 and 12

\begin{tabular}{|l|c|c|c|c|c|c|c|}
\hline \multirow{2}{*}{\multicolumn{1}{c|}{ Sample }} & \multirow{2}{*}{$\mathbf{M M T}$} & \multicolumn{3}{|c|}{$\mathbf{C L}$} & \multicolumn{3}{c|}{$\mathbf{2 : 1} \mathbf{C L M}$} \\
\cline { 3 - 8 } & & $\mathbf{p H}=\mathbf{3}$ & $\mathbf{p H}=\mathbf{7}$ & $\mathbf{p H}=\mathbf{1 2}$ & $\mathbf{p H}=\mathbf{3}$ & $\mathbf{p H}=\mathbf{7}$ & $\mathbf{p H}=\mathbf{1 2}$ \\
\hline Zeta potential, $\zeta[\mathrm{mV}]$ & $-32.3 \pm 3.5$ & $+14.6 \pm 3.5$ & $-5.3 \pm 1.3$ & $-19.8 \pm 2.0$ & $+33.5 \pm 0.9$ & $-35.9 \pm 2.7$ & $-40.4 \pm 5.3$ \\
\hline Hydrodynamic diameter, $D[\mathrm{~nm}]$ & $642 \pm 31$ & $179 \pm 4$ & $179 \pm 4$ & $240 \pm 1$ & $286 \pm 2$ & $431 \pm 19$ & $300 \pm 3$ \\
\hline
\end{tabular}


bly disperse in aqueous solution, which can also be verified by the zeta potential of CLM in Table 1 and be visualized in Figure 3. The CLM suspensions with a mass ratio $<2: 1$ or prepared at alkaline $\mathrm{pH}$ undergo sedimentation after $48 \mathrm{~h}$, whereas the CLM suspensions with a mass ratio $\geq 2: 1$ prepared at acidic and neutral $\mathrm{pH}$ are stable. Furthermore, the stable CLM suspensions can build a paper material just by vacuum filtration (Figure 3, right), implying structure change of CLM hybrid materials.

\subsection{Structure and morphology of CLM}

The degree of exfoliation or intercalation of MMT is usually characterized by XRD. The XRD patterns of MMT, CL and CLM hybrid materials prepared at different $\mathrm{pH}$ are shown in Figure 4. The diffraction peaks of MMT prepared at $\mathrm{pH}$ of 3, 7 and 12 are located at $2 \theta=5.85,5.91$ and $7.14^{\circ}$, respectively corresponding to basal spacing $d_{001}$ of $1.24,1.49$ and $1.50 \mathrm{~nm}$ calculated by the Bragg equation. It can be observed that no diffraction peak appears in the sample of CL, thereby having no effect on the detection of XRD for CLM hybrid materials. In the XRD patterns of the CLM with mass ratios of $0.1: 1$ and 0.2:1 prepared at $\mathrm{pH}$ of 7 and 3, weak and broad peaks appear at lower angles corresponding to $d_{001}=$ $1.53-1.57 \mathrm{~nm}$, indicating the slight intercalation of
CL into the interlayer gallery of MMT. Taking account of the thickness of MMT platelets $(0.96 \mathrm{~nm})$, the interlayer distances $(\Delta d)$ of those CLM are 0.57$0.61 \mathrm{~nm}$, which roughly represents the layer thickness of CL intercalated into MMT. Such small layer thicknesses of CL imply very low $M_{\mathrm{W}}$ for the intercalated CL. However, it is widely recognized that the small chain length polycations in a polydisperse mixture may be displaced by high $M_{\mathrm{W}}$ polycations [35]. Hence, when the mass ratio increases to 1:1 (near stoichiometric point), the high $M_{\mathrm{W}} \mathrm{CL}$ replaces the low $M_{\mathrm{W}} \mathrm{CL}$, giving the CLM larger $d_{001}$ of 2.89-3.66 corresponding to $\Delta d=1.93-2.70 \mathrm{~nm}$, which coincides with the thickness of one layer of disk-like lignin flat on solid surface as mentioned above (about $2 \mathrm{~nm}$ ). Continuing to increase the mass ratio in the $\mathrm{pH}=7$ and 3 systems, no obvious peak is found in the $2 \theta$ range from $2^{\circ}$ (corresponding to $d_{001}=$ $4.41 \mathrm{~nm}$ ) to $10^{\circ}$, implying possible exfoliation of MMT or basal spacing larger than $4.41 \mathrm{~nm}$. For the CLM prepared at $\mathrm{pH}$ of $12, \mathrm{XRD}$ results show an intercalated structure for the CLM and the basal spacing increases with increasing the mass ratio of CL to MMT. The basal spacing is mainly divided into two parts: low $M_{\mathrm{W}} \mathrm{CL}$ intercalated $d_{001}$ (1.38$1.57 \mathrm{~nm}$, corresponding to $\Delta d=0.42-0.61 \mathrm{~nm})$ and high $M_{\mathrm{W}}$ CL intercalated $d_{001}(1.94-3.94 \mathrm{~nm}$, corre-

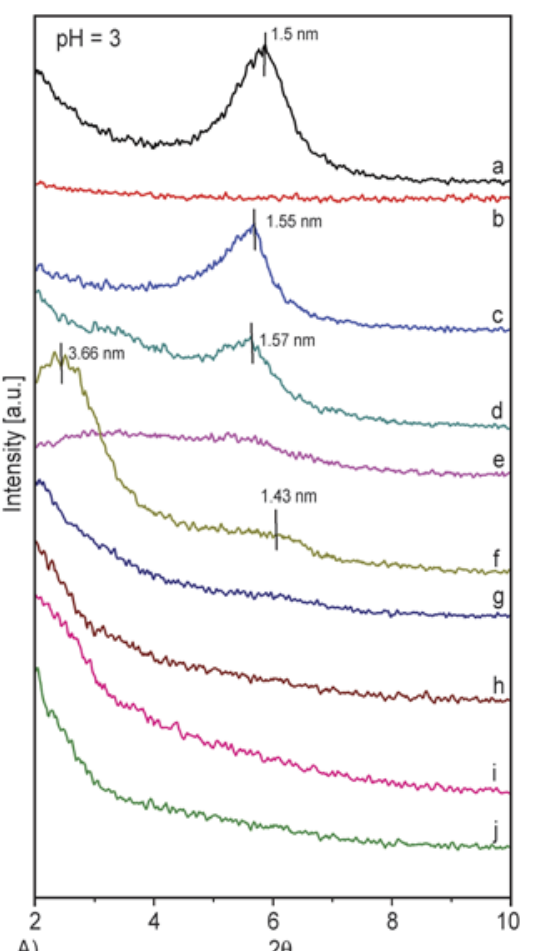

A) $2 \theta$
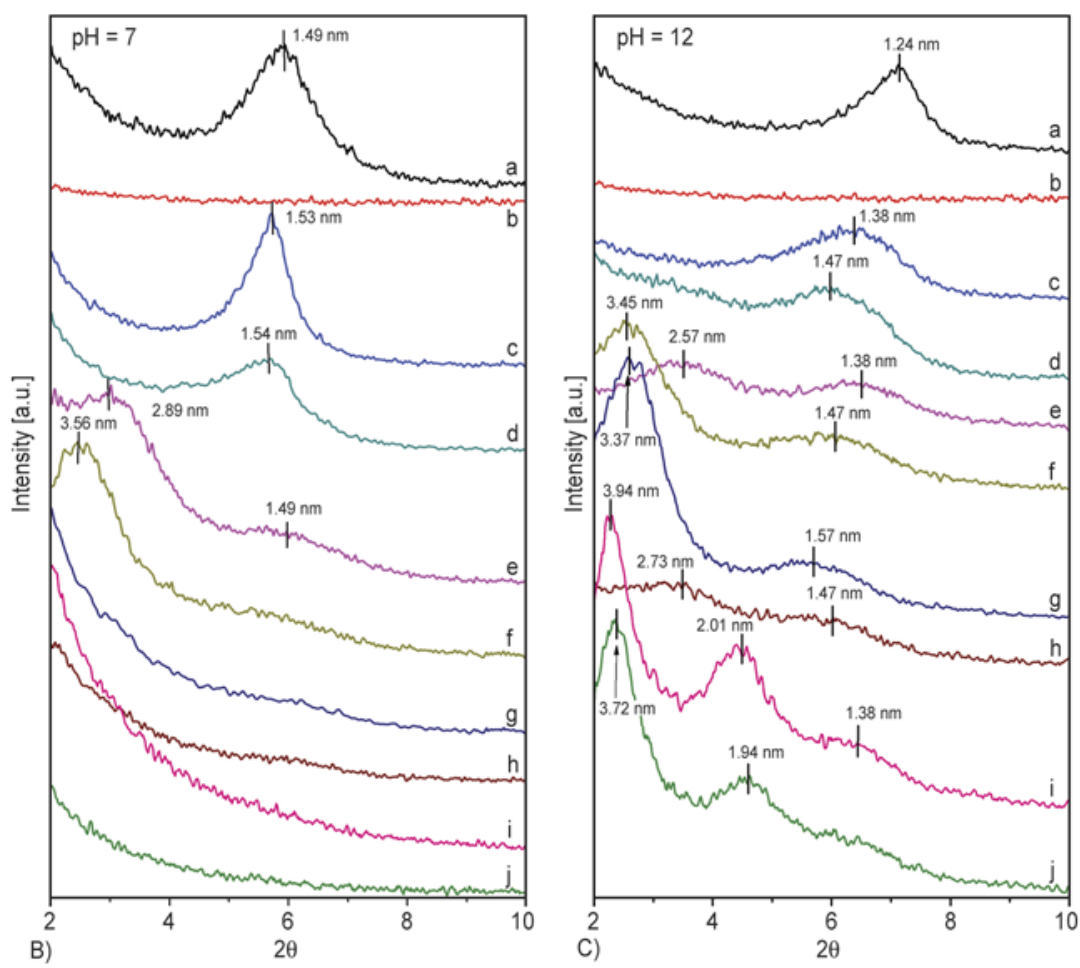

Figure 4. XRD patterns of (a) MMT, (b) CL and CLM hybrid materials with CL-MMT mass ratio of (c) 0.1:1, (d) 0.2:1, (e) $0.4: 1$, (f) $0.8: 1$ (g) 2:1, (h) 4:1, (i) 6:1 and (j) 8:1, prepared at pH of (A) 3, (B) 7 and (C) 12 


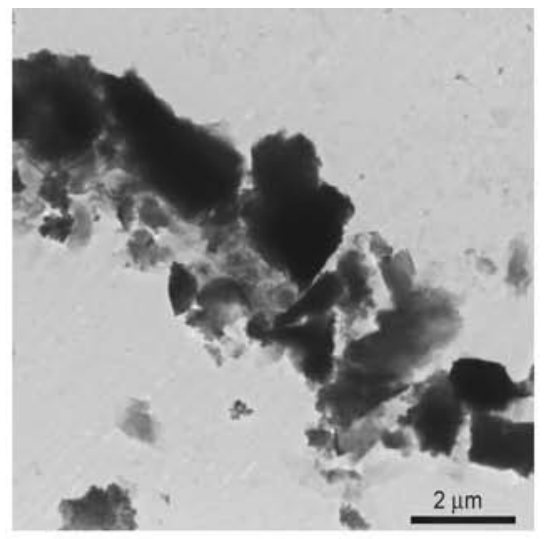

a)

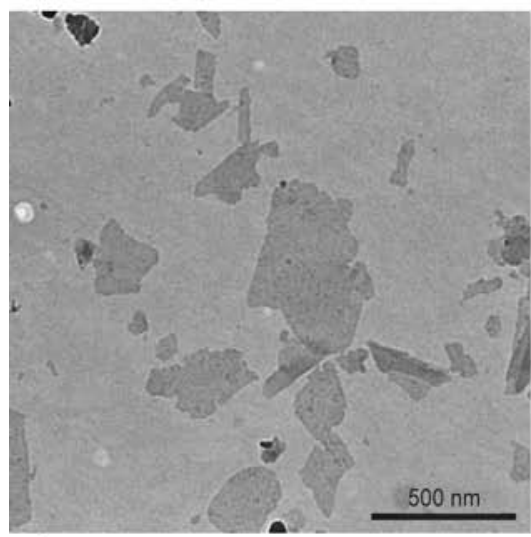

c)

d)

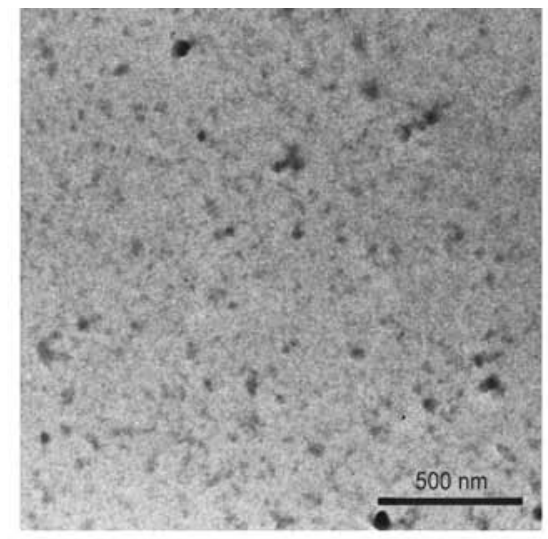

b)

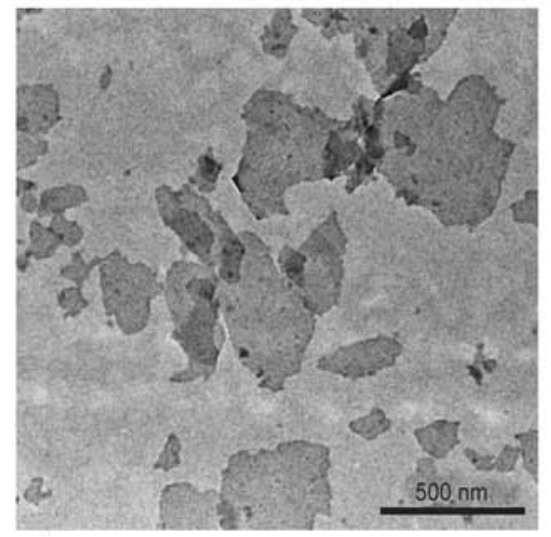

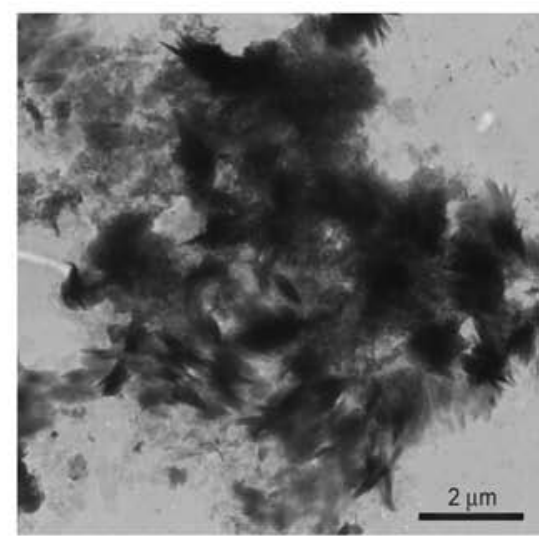

Figure 5. TEM images of (a) pristine MMT, (b) CL and CLM with mass ratio of 2:1 prepared at pH of (c) 3, (d) 7 and (e) 12

sponding to $\Delta d=0.98-2.98 \mathrm{~nm})$. On the basis of the $\mathrm{XRD}$ results, the structure of CLM is tunable by adjustment of $\mathrm{pH}$ and the mass ratio of CL to MMT. Owing to the limitation of detection range of XRD measurements, basal spacing larger than $4.41 \mathrm{~nm}$ or fully exfoliated structure cannot be found. To further reveal the structure of CLM hybrid materials, TEM and AFM measurements are employed. As shown in Figure 5a, MMT forms dense tactoids without any exfoliation once drying. CL displays a spotted structure with a diameter less than $100 \mathrm{~nm}$ (Figure 5b), which is very different from the hydrodynamic diameter of CL in aqueous solution obtained from DLS measurement (Table 1). It is reasonable to believe

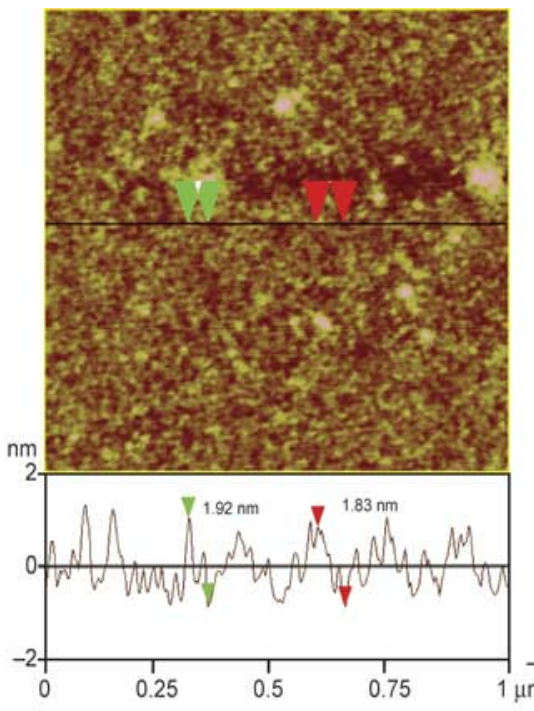

a)

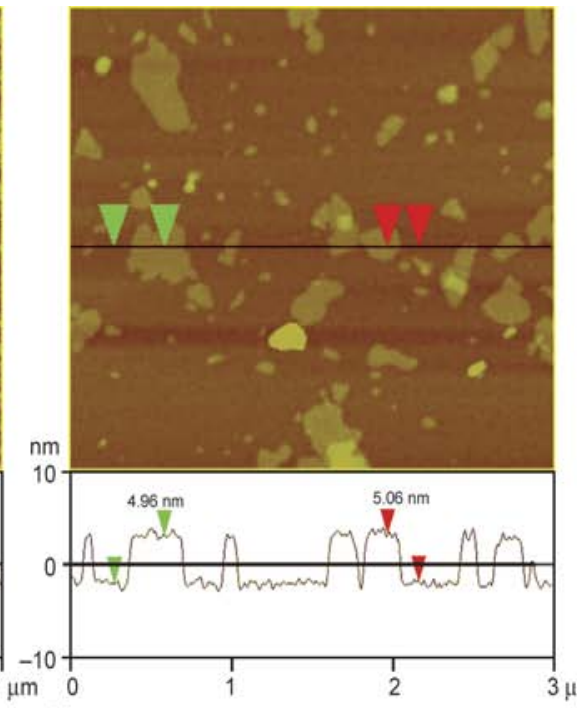

b)

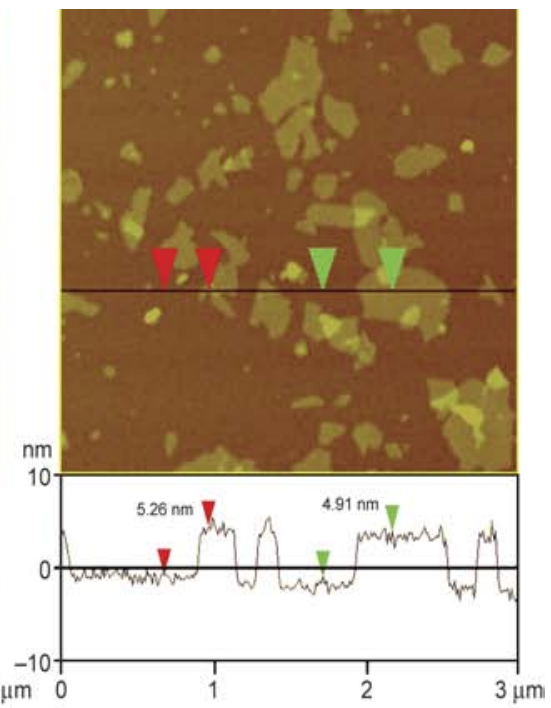

c)

Figure 6. Representative AFM height images and corresponding thickness analysis of (a) CL and CLM with mass ratio of 2:1 prepared at $\mathrm{pH}$ of (b) 3 and (c) 7 
that CL as swollen spherical polyelectrolyte in aqueous solution will seriously shrink once drying. Moreover, from the AFM height image of CL, the thickness of CL granules is about $2 \mathrm{~nm}$ (Figure 6a), indicating the disk-like conformation of CL on solid surface. In comparison to pristine MMT, the CLM hybrid materials with mass ratio of 2:1 prepared at $\mathrm{pH}$ of 3 and 7 are individual dispersed irregular lamellas on carbon film with lateral dimension of about several hundred nanometers (Figure $5 \mathrm{c}$ and $5 \mathrm{~d}$ ). On the lamellas surface, a large amount of obscure CL spots can be found. In addition, from the AFM height images of the CLM with a mass ratio of $2: 1$ prepared at $\mathrm{pH}$ of 3 and 7, the thickness of the CLM sheets is about $5 \mathrm{~nm}$ (Figure 6b and 6c), which is approximately equal to the combined thickness of one MMT platelet and two disk-like CL layers. The same results are also found in the CLM with mass ratio $\geq 2: 1$ prepared at $\mathrm{pH}$ of 3 and 7 . Hence, combined with the results of TEM and AFM measurements, we can sufficiently confirm that MMT can be completely exfoliated into individually dispersed nanosheets as plane templates to anchor two layers of disk-like CL, when the CLM hybrid materials with mass ratio $\geq 2: 1$ are prepared at $\mathrm{pH}$ of 3 and 7 . In Figure 5e, it can be seen that the CLM with a mass ratio of 2:1 prepared at $\mathrm{pH}$ of 12 exhibits swollen morphologies, indicating that CL is trapped in the MMT interlayer galleries to form an intercalated structure. Overall, the TEM and AFM observations are highly consistent with the above XRD results.

\subsection{Adsorption mechanism and interactions between $C L$ and MMT}

The schematic illustration of adsorption mechanism and interactions between CL and MMT are depicted in Figure 7. It is generally accepted that little adsorption and no intercalation into clay interlayer galleries occur with negatively charged polymer due to the initial electrostatic repulsion between the polymer and clay surface [39]. In our investigated systems, the intercalated structure of the CLM prepared at $\mathrm{pH}$ of 12 seems to be at odds with the theoretical expectation. It may imply some special interactions between CL and MMT. Beall and Gross [40] reported that ion-dipole interactions could drive organic compounds with partial negative charges into MMT interlayer galleries. This phenomenon was also observed by Dang in the system of silk fibroin and MMT [41]. Although many polar groups in CL can interact with the interlayer cations via iondipole interactions, we propose that stronger noncovalent interactions, cation- $\pi$ interactions between the interlayer cations and aromatic rings of $\mathrm{CL}$, are dominant driving force for the adsorption of negatively charged CL onto MMT. Cation- $\pi$ interactions are of the strongest noncovalent interactions and operate over van der Waals distances (instead of typical ion-dipole distances). Typically, water soluble cations have greater interaction energy with benzene rings than with water [42]. Since the intercalation of negatively charged organic molecules into MMT interlayer galleries can be realized via ion-dipole interactions, the stronger cation- $\pi$ inter-

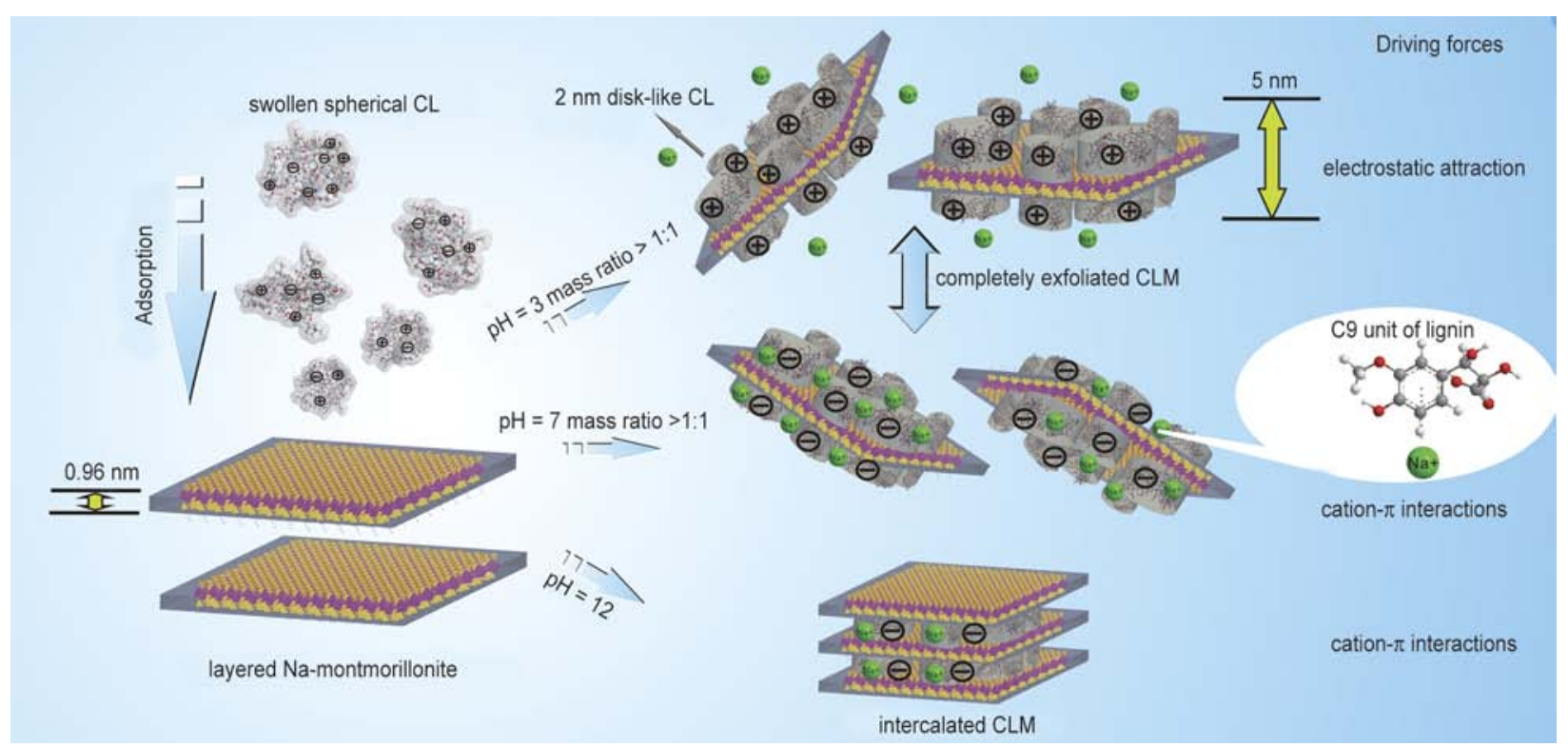

Figure 7. Schematic illustration of adsorption mechanism and interactions between CL and MMT 
actions should be more responsible for the intercalated structure of the CLM hybrid materials prepared at $\mathrm{pH}$ of 12. On the other hand, because of the polydispersity of lignin molecules, low $M_{\mathrm{W}}$ lignin has a relatively small amount of anionic groups and thus the synthesized CL with low $M_{\mathrm{W}}$ has a relatively large amount of positive charges in return. At high $\mathrm{pH}$, some low $M_{\mathrm{W}} \mathrm{CL}$ molecules are even positively charged, which are easier to interact with MMT and enter into MMT interlayer galleries via electrostatic attractive interactions or cation- $\pi$ interactions. However, the intercalation by low $M_{\mathrm{W}} \mathrm{CL}$ just results in relatively small expansion in basal spacing. The larger basal spacing and even the exfoliated structure must arise from the intercalation of high $M_{\mathrm{W}} \mathrm{CL}$ via cation- $\pi$ interactions. Nonetheless, low $M_{\mathrm{W}} \mathrm{CL}$ must firstly enter the MMT interlayer galleries to enlarge the interlayer distance for the subsequent entrance of high $M_{\mathrm{W}} \mathrm{CL}$ via cation- $\pi$ interactions. Disappointingly, only intercalated structure is achieved at $\mathrm{pH}$ of 12 for all investigated mass ratios. This can be attributed to weak attractive interactions between natively charged MMT and CL, which cannot completely overcome the electrostatic repulsion at such high $\mathrm{pH}$. However, cation- $\pi$ interactions are more remarkable for the CLM prepared at $\mathrm{pH}$ of 7, which results in an exfoliated structure. Although the $\mathrm{CL}$ at $\mathrm{pH}$ of 7 exhibits a nearly electroneutral polymer $(-5.3 \pm 1.3 \mathrm{mV}$, Table 1$)$, the CLM with mass ratio of $2: 1$ prepared at $\mathrm{pH}$ of 7 has a zeta potential of $-35.9 \pm 2.7 \mathrm{mV}$, which is just a little bit lower than that of pristine MMT $(-32.3 \pm 3.5 \mathrm{mV}$, Table 1), demonstrating that the CL adsorbed onto the MMT platelet surfaces exhibits much more electronegativity. It can be explained as below: the nearly electroneutral CL has the lower electrostatic repulsion towards MMT. As a result, the positively charged sites of CL are able to approach MMT platelets to balance the negatively charged sites at MMT platelet surfaces. Simultaneously, the interlayer cations of MMT can bond to the aromatic rings of CL via cation- $\pi$ interactions to compensate the negative charges of CL. In this way, the electrostatic repulsion between the MMT and negatively charged CL is inhibited to avoid desorption of CL from MMT. For the CLM prepared at $\mathrm{pH}$ of 3 , the $\mathrm{CL}$ is positively charged at such $\mathrm{pH}$ and can interact with negatively charged MMT via electrostatic attractive interactions. As electrostatic attractive interactions are stronger than cation- $\pi$ interactions, the affinity constant and Gibbs free adsorption energy at $\mathrm{pH}$ of 3 are highest. Additionally, on basis of the results of DLS and AFM measurements for CL, the conformation of CL molecules changes from extended spherical microgel with a mean hydrodynamic diameter of about $200 \mathrm{~nm}$ to disc -like sheet with a thickness of about $2 \mathrm{~nm}$, when CL adsorbed onto MMT. This conformation change can provide entropy gain to drive the adsorption of CL onto MMT. Overall, the repulsion interactions decrease gradually and the attractive interactions become stronger with decreasing $\mathrm{pH}$, resulting in stronger adsorption of $\mathrm{CL}$ onto MMT and different charge status.

\subsection{Glass transition behavior}

Further information can be estimated from the glass transition temperature $\left(T_{\mathrm{g}}\right)$ of CLM hybrid materials (Figure 8). Compared to the $T_{\mathrm{g}}$ of lignin $\left(170^{\circ} \mathrm{C}\right)$, $\mathrm{CL}$ has a higher $T_{\mathrm{g}}$ of $211^{\circ} \mathrm{C}$ due to strong intramolecular cation- $\pi$ interactions between quaternary ammonium cations and aromatic rings in CL macromolecules. For CLM hybrid materials, the thermal transition behavior of CLM is mainly originated from the segment motion of CL molecules, which can be completely confined by MMT platelets only if the interaction between CL and MMT platelets is strong enough. Beall et al. reported that there are three regions around the clay platelets: the surface modifier region, the constrained polymer region, and the unconstrained polymer region. The surface modifier region is about $1-2 \mathrm{~nm}$, while the constrained polymer region may extend $50-100 \mathrm{~nm}$ away from the clay platelet surface [43]. Therefore, DSC does not detect any traces of thermal transitions for the CLM with a complete exfoliated structure, where the motion of disk-like $\mathrm{CL}$ with a thickness of about $2 \mathrm{~nm}$ is completely constrained by MMT platelets (i.e., the DSC curves of the CLM with mass ratio $\geq 2: 1$ prepared at $\mathrm{pH}$ of 7 and 3 ). Similarly, the neatly intercalated CLM should have no thermal transition since the intercalated distance is usually less than the constrained polymer region. Obviously, the CLM prepared at $\mathrm{pH}$ of 12 is neatly intercalated without any CL adsorbed on the external surfaces of MMT tactoids. However, other CLM hybrid materials prepared at $\mathrm{pH}$ of 3 and 7 with an intercalated structure exhibit a lower $T_{\mathrm{g}}$ at 140 $148^{\circ} \mathrm{C}$ or original $T_{\mathrm{g}}$. This can be attributed to the fact that lots of $\mathrm{CL}$ is adsorbed on the external surfaces of MMT tactoids at $\mathrm{pH}$ of 3 and 7, which cannot be 

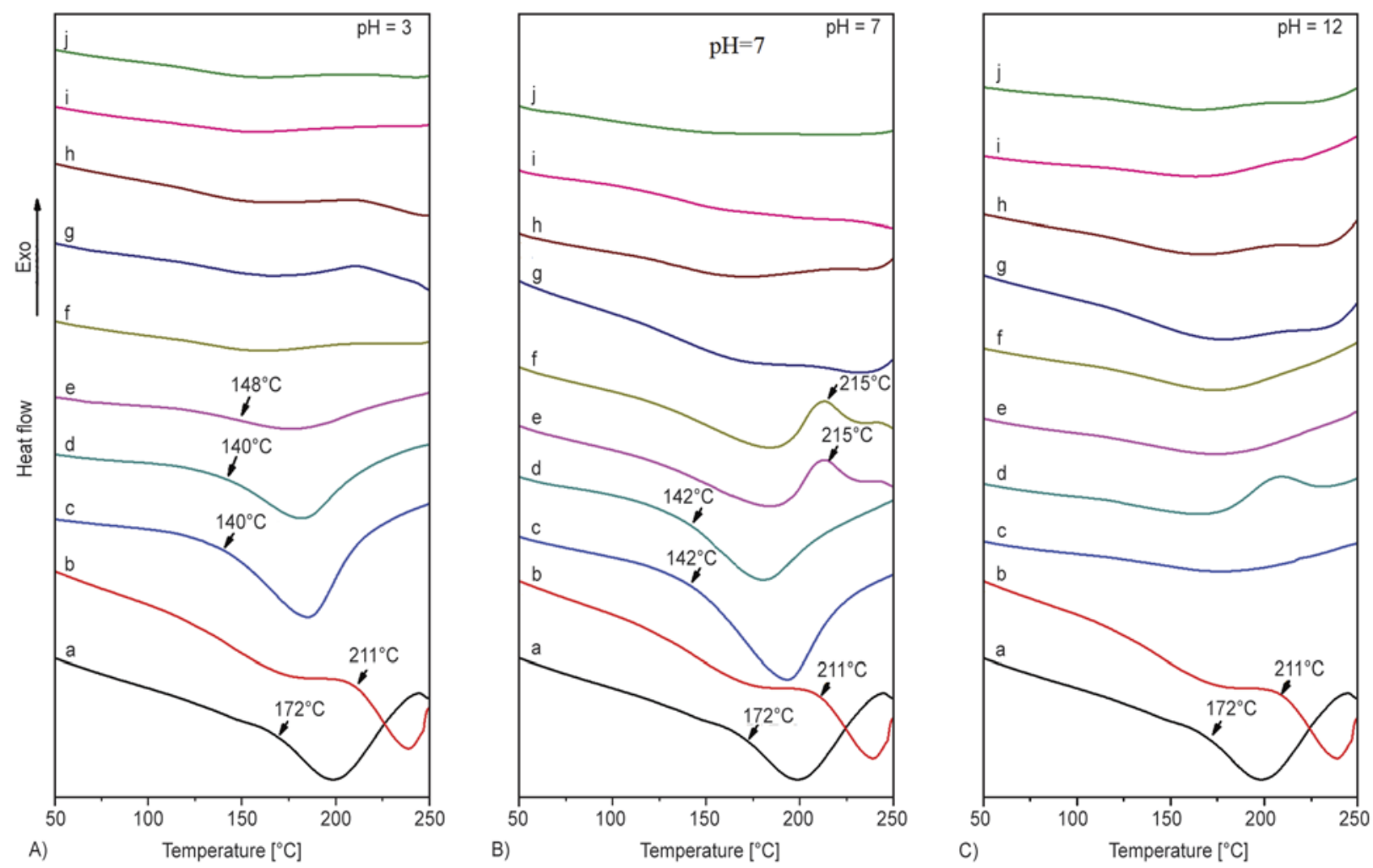

Figure 8. DSC curves of (a) lignin, (b) CL and CLM hybrid materials respectively prepared at $\mathrm{pH}$ of 3,7 and 12, having CL-MMT mass ratio of (c) $0.1: 1$, (d) $0.2: 1$, (e) $0.4: 1$, (f) $0.8: 1$, (g) $2: 1$, (h) $4: 1$, (i) $6: 1$ and (j) $8: 1$

restricted by MMT platelets. Moreover, the hydrogen bonding between CL and MMT can weaken the interactions among $\mathrm{CL}$ molecules, thus resulting in lower $T_{\mathrm{g}}$. DSC results have demonstrated that the mobility of CL molecules adsorbed onto MMT platelet surface is completely confined. In another word, the CL anchored onto MMT platelets is a steady 2D-nanosheet.

\subsection{SBR/CLM composites}

In previous reports, lignin has been proved to be an effective carbon black replacement for SBR via complicated latex co-coagulating procedure $[44,45]$. In fact, the applications of lignin in rubber industry are seriously limited due to the extremely slow coagulating rate, as shown in Figure 9a. Even if the rate can be improved by heating the mixture solution, not all lignin can be incorporated into rubber and lignin will form thermal irreversible agglomerates to deteriorate the performance of rubber. However, the coagulating rate is substantially improved for SBR/CLM mixture, which can be attributed to the reduction of surface activity of lignin caused by the restriction effect of MMT.
The dispersion status of CLM in SBR matrix is also studied by XRD. As shown in Figure 9b, there is no obvious diffraction peak in all of sample as pure CLM exhibits, implying homogenous dispersion of CLM in SBR matrix. But the absence of peaks is also possibly originated from the lack of sensitivity of apparatus. Hence, the actual mass ratio of CL to MMT is determinated by TGA. As shown in Figure $9 \mathrm{c}$, according to the residual char rate of MMT, CL and CLM, the actual mass ratio of CL to MMT is 4.16:1. Namely, in $10 \mathrm{phr}$ CLM filled SBR matrix, the loading of CL is equivalent to about $8 \mathrm{phr}$ while MMT is about $2 \mathrm{phr}$. Such a MMT loading is able to be detected by XRD, at least in the sample of SCLM-10. Due to the barrier characteristic of MMT, the decomposition peaks of CL at 264.7 and $365.3^{\circ} \mathrm{C}$ shift to higher temperatures of 319.6 and $375.7^{\circ} \mathrm{C}$ in the sample of CLM respectively, and the weight loss rate of CLM is obviously reduced, demonstrating excellent thermal stability of CLM.

SEM images of SBR/CLM composites are shown in Figure 10a and 10b. It is clearly seen that CLM as protuberances showing an obvious aspect ratio is well dispersed and embedded into SBR matrix. The 

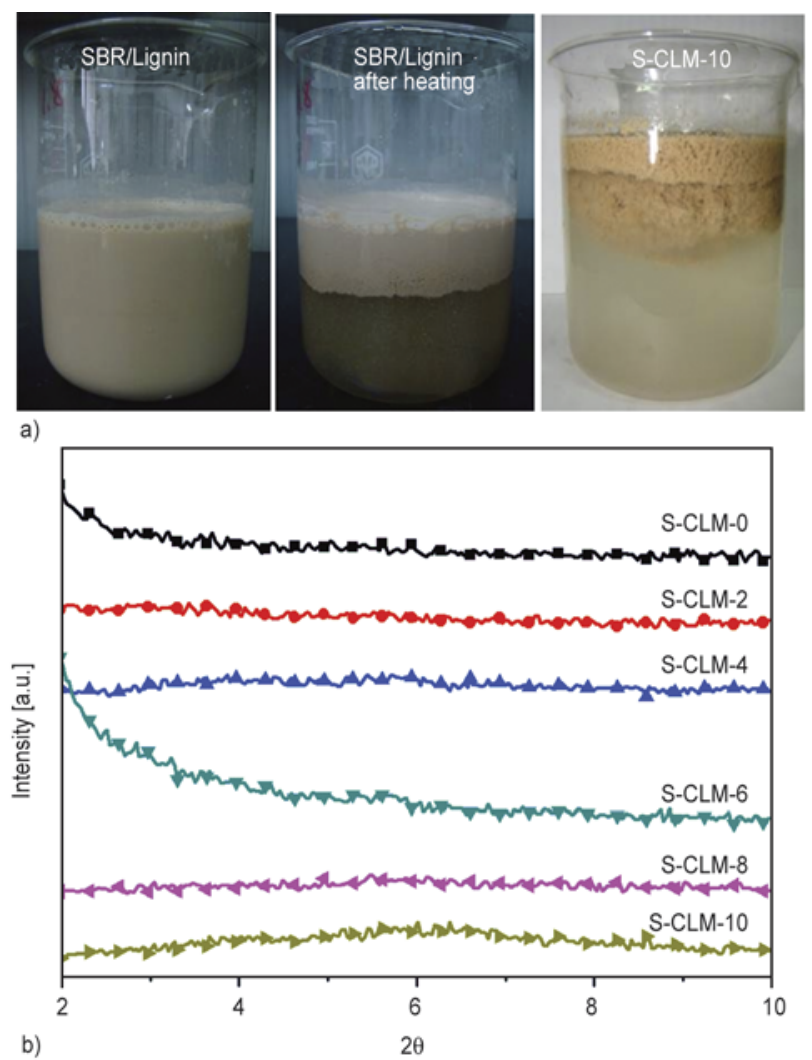

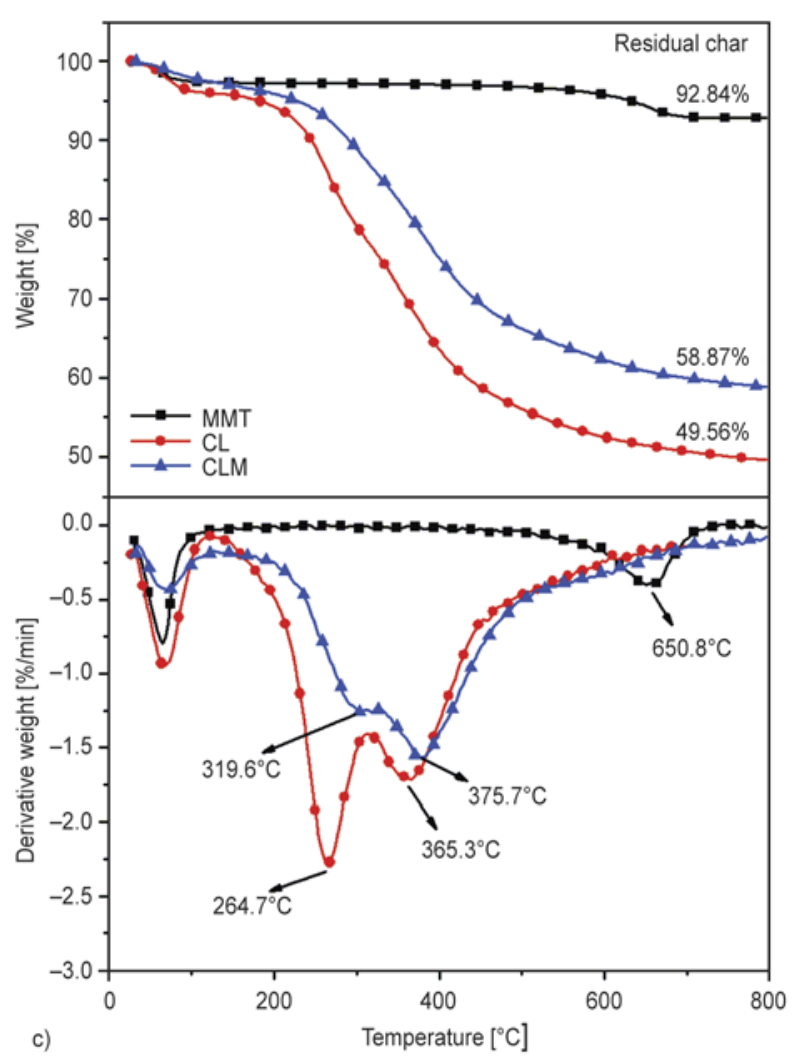

Figure 9. (a) Digital photos of co-coagulation of SBR latex with $10 \mathrm{phr}$ lignin and CLM, (b) XRD patterns of SBR/CLM vulcanizates, (c) TG (top right) and DTG (bottom right) curves of MMT, CL and CLM

interface between CLM and SBR matrix is very blurry, implying good compatibility and strong interface adhesion between them. Actually, the interface structure is very special with the presence of compatibilizer CGE, which will be disclosed by DMA in the following text. The dispersion of CLM is further investigated by TEM. As shown in Figure 10c and 10d, CLM nanosheets are observed as plane-on dark domains throughout SBR matrix with a lateral dimension of several hundred nanometers, indicating the completely exfoliation of CLM. In addition, some CLM nanosheets are embedded into SBR matrix as edge-on dark lines with interlayer distance more than $5-10 \mathrm{~nm}$. The results adequately demonstrate the uniform dispersion of CLM in SBR matrix.

As shown in Figure 11a, the $\tan \delta$ peaks of SBR/CLM composites shift to lower temperature and the glass transition temperature $\left(T_{\mathrm{g}}\right)$ continually decreases from -46.2 to $-52.2^{\circ} \mathrm{C}$ as increasing CLM loading, accompanying with increased loss tangent peak height. Additionally, the curves of the storage modulus $E^{\prime}$ vs. Temperature of the composites are also shown in Figure 11b. The $E^{\prime}$ of SBR/CLM composites increases with the CLM loading above $0^{\circ} \mathrm{C}$, indicating the increase of the stiffness of the materials.
For polymer nanocomposites, $T_{\mathrm{g}}$ has been reported to increase, decrease or remain unchanged in previous researches, depending on the interface interactions of composites [46-48]. In our system, CGE is used as compatibilizer for SBR/CLM composites, which owns two different functional groups (epoxy groups and double bonds). Owing to the double bonds of CGE, it can be grafted onto the SBR molecule during curing process and acts as a plasticizer to lower $T_{\mathrm{g}}$. when no CLM is added, CGE grafted SBR molecule is analogous to comb-like polymer chain and can mutually crosswise arrange in a relatively compact formation due to steric hindrance, as shown in Figure 12. However, once loading CLM, the comb-like SBR molecules are separated from each other by CLM. Moreover, not all epoxy groups of CGE can be opened under heating and bonded to the surface of CLM. Some of those can interact with CLM through hydrogen bonding. Consequently, in this way, the free volume of chain segments of SBR molecule is enlarged and the $T_{\mathrm{g}}$ of composites decreases with increasing CLM loading.

In rubber based nanocomposites, very strong chemical bonding or excessive chemical bonds between the rubber matrix and nanofillers are not acknowledged, because it may greatly restrict the slippage 


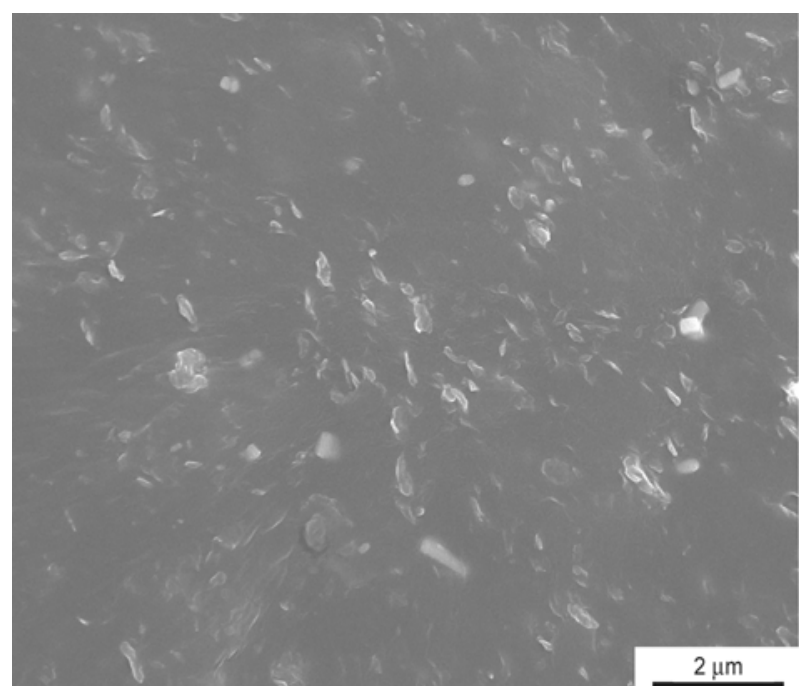

a)

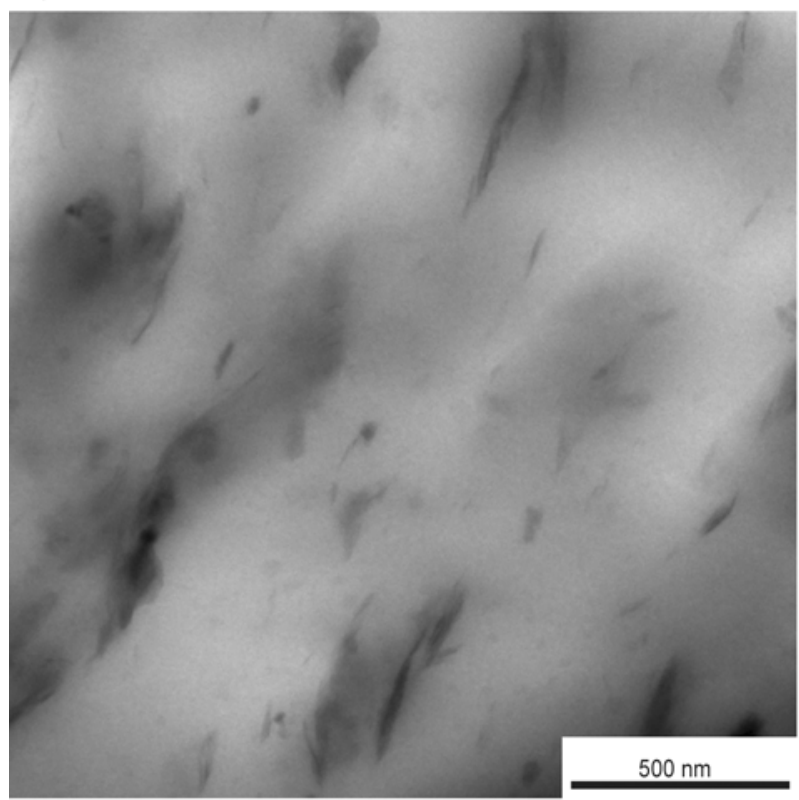

c)

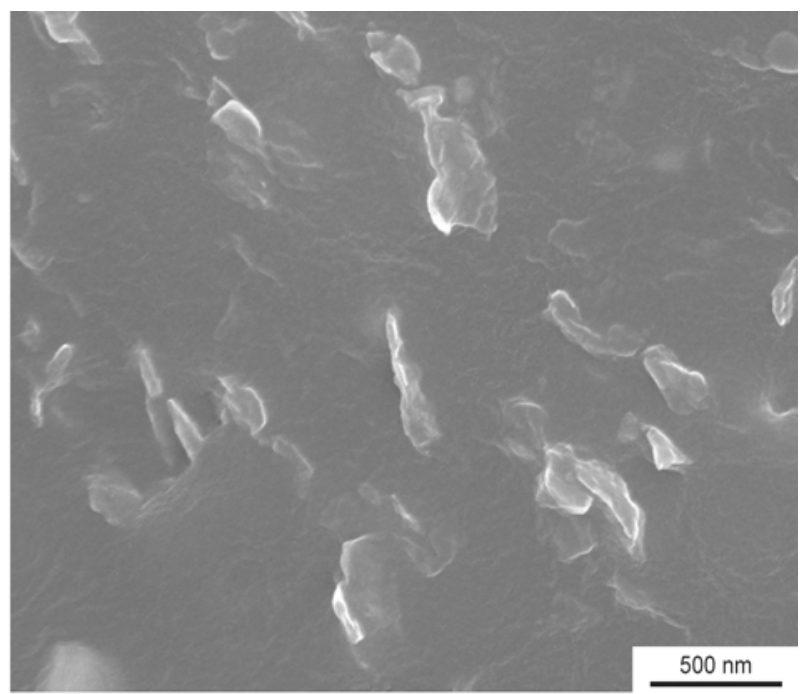

b)

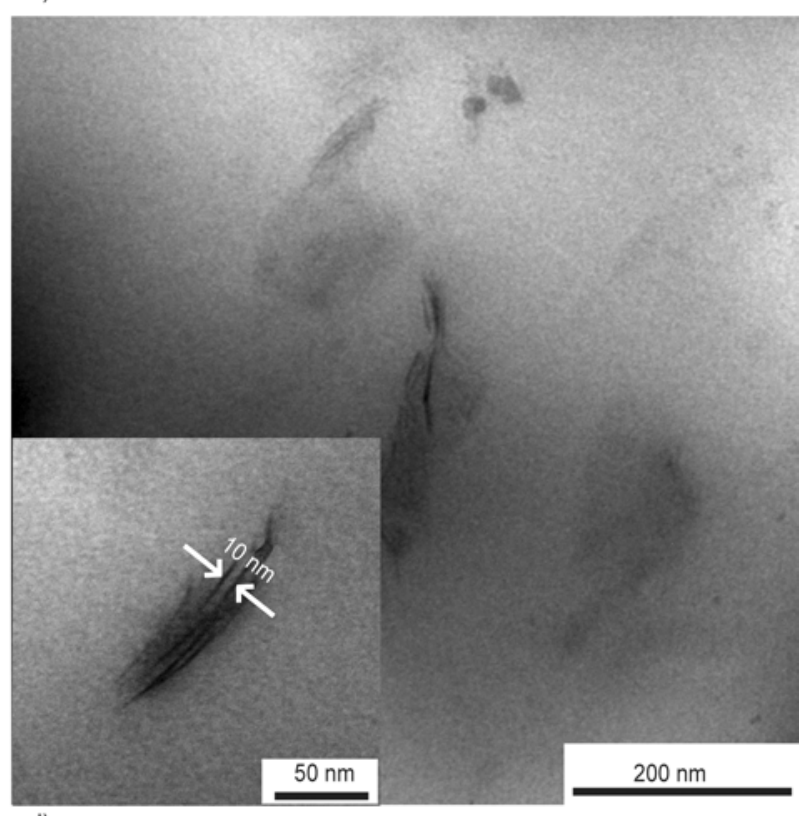

d)

Figure 10. SEM $(a, b)$ and TEM $(c, d)$ photos of S-CLM-10 at different magnifications
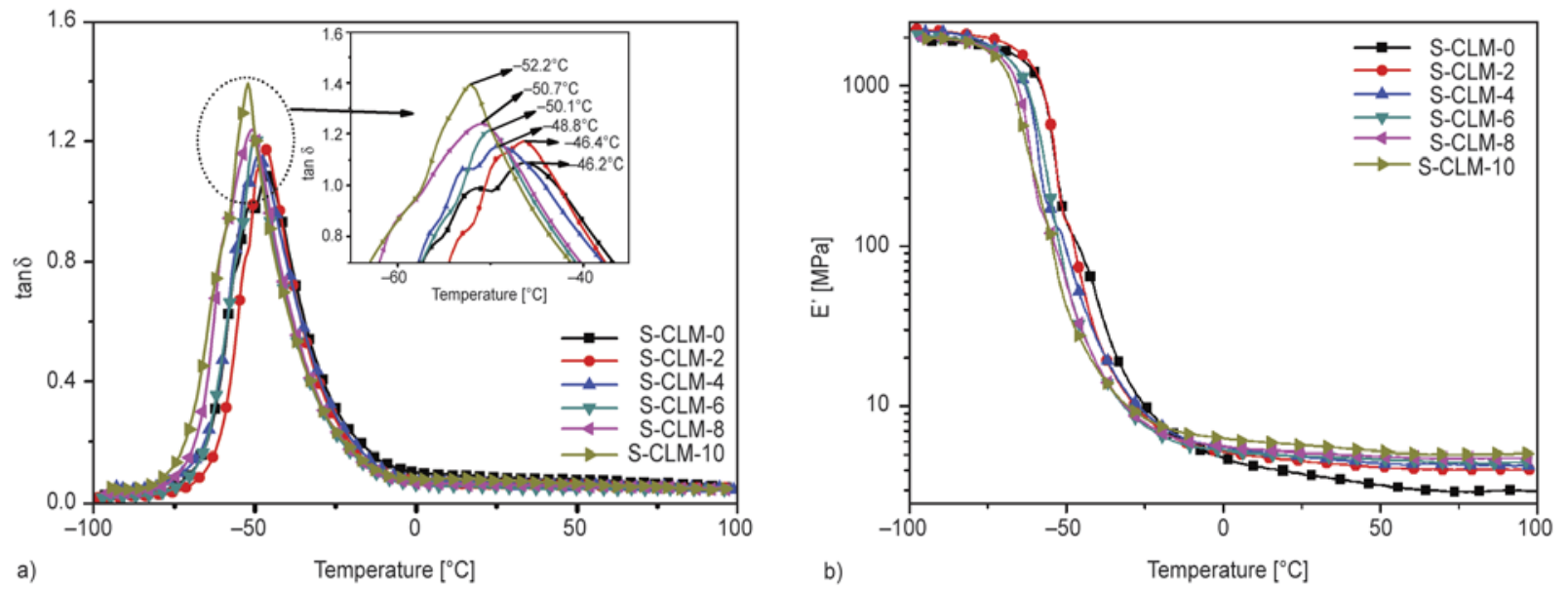

Figure 11. $\tan \delta$ (a) and storage modulus $E^{\prime}(\mathrm{b})$ of SBR/CLM composites as a function of temperature

of rubber molecule chain, leading to the occurrence of fracture at decreased strain for centralized stress.
In contrast, the CGE grafted SBR can interact with CLM via moderate chemical bonds and lots of 


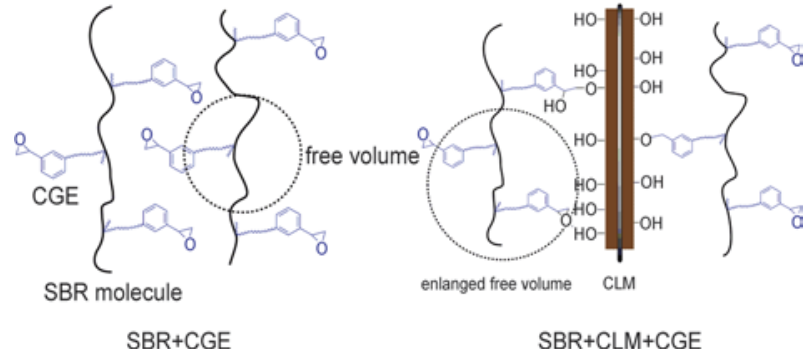

Figure 12. Schematic illustration of the interface structure of SBR/CLM composites

hydrogen bonding, which is in favor of SBR chains slipping along the surface of CLM to form orientated induced straight chains and uniformly distribute the external force. Hence, as shown in Figure 13 and Table 2, the ultimate stress of SBR/CLM composites can be extremely improved at higher deformation and the tensile modulus is also increased with increasing CLM loading, owing to the slippage of SBR chains to relieve stress concentration and moderate covalent bonding to transfer stress from matrix to CLM. Especially, the $300 \%$ modulus is substantially improved as increasing CLM loading, indicating a stronger filler-rubber interactions. With the inclusion of only $10 \mathrm{phr}$ CLM, the ulti-

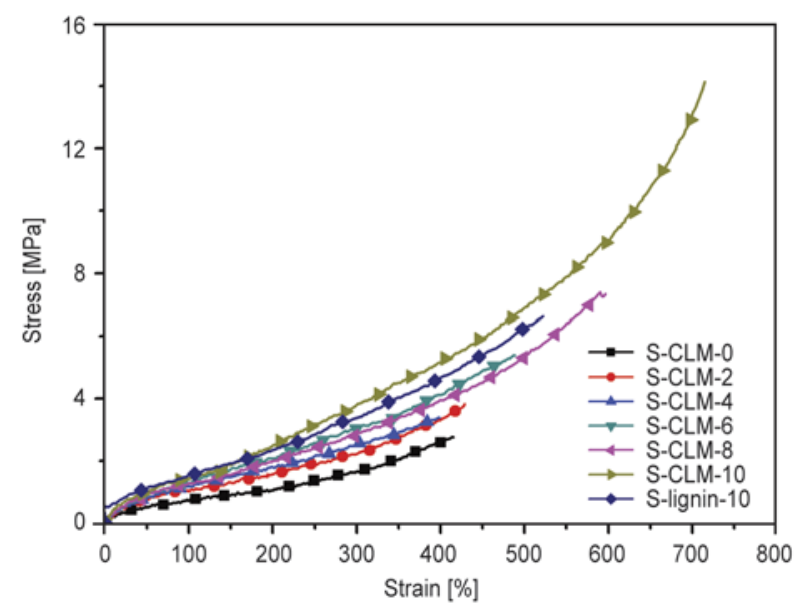

Figure 13. Stress-strain curves of SBR/CLM composites and S-lignin-10 mate stress for S-CLM-10 can be increased to about 14.14 $\mathrm{MPa}$, which is obviously superior to the properties of S-lignin-10 and those lignin-based SBR composites at the same lignin loading as previously reported [49].

\section{Conclusions}

The adsorption of CL onto MMT gave rise to a series of CLM hybrid materials with different structures. The adsorption isotherms showed very high and $\mathrm{pH}$-dependent affinity between CL and MMT. The structures of CLM were characterized by XRD, TEM and AFM. It was found that MMT was neatly intercalated by $\mathrm{CL}$ at $\mathrm{pH}$ of 12 , whereas MMT could be completely exfoliated into individually dispersed nanosheets covered by two layers of $\mathrm{CL}$ at $\mathrm{pH}$ of 7 and 3. The differences in structure strongly depended on the interactions between CL and MMT. Therefore, a schematic illustration was proposed to describe the adsorption mechanism, interactions between CL and MMT as well as the conformation features of CL anchored onto the surface of MMT platelets. The zeta potential measurements combined with aforementioned characterization techniques revealed that cation- $\pi$ interactions was a dominant driving force for adsorption at alkaline and neutral $\mathrm{pH}$, while the electrostatic attractive interactions drove the adsorption at acidic $\mathrm{pH}$. Moreover, the different sizes of CL in AFM and DLS measurement confirmed the conformation change of CL from swollen spherical microgel to disk-like CL with a thickness of about $2 \mathrm{~nm}$. DSC results indicated the strong confinement of CL molecules by MMT platelets. Finally, the incorporation of CLM into SBR via latex co-coagulating showed a higher coagulating rate compared to lignin, and the performance of composites was substantially improved by just adding $10 \mathrm{phr}$ CLM. Hence, the plane-interface-induced method for preparing individually dispersed 2D CLM nanosheets provides a promising

Table 2. The mechanical properties of SBR/CLM composites and S-lignin-10

\begin{tabular}{|l|c|c|c|c|c|c|}
\hline \multicolumn{1}{|c|}{ Sample } & $\begin{array}{c}\text { Modulus at 100\% } \\
\text { [MPa] }\end{array}$ & $\begin{array}{c}\text { Modulus at 300\% } \\
{[\mathbf{M P a}]}\end{array}$ & $\begin{array}{c}\text { Tensile strength } \\
{[\mathbf{M P a}]}\end{array}$ & $\begin{array}{c}\text { Elongation at break } \\
{[\mathbf{\%}]}\end{array}$ & $\begin{array}{c}\text { Permanent set } \\
{[\mathbf{\%}]}\end{array}$ & $\begin{array}{c}\text { Hardness } \\
\text { Shore A }\end{array}$ \\
\hline S-CLM-0 & 0.80 & 1.62 & 2.73 & 421 & 6 & 43 \\
\hline S-CLM-2 & 1.06 & 2.29 & 3.46 & 431 & 6 & 47 \\
\hline S-CLM-4 & 1.18 & 2.58 & 3.39 & 407 & 4 & 48 \\
\hline S-CLM-6 & 1.33 & 3.04 & 4.98 & 473 & 6 & 48 \\
\hline S-CLM-8 & 1.27 & 2.88 & 7.20 & 588 & 9 & 48 \\
\hline S-CLM-10 & 1.47 & 3.88 & 14.14 & 718 & 16 & 48 \\
\hline S-lignin-10 & 1.45 & 3.38 & 6.71 & 516 & 8 & 47 \\
\hline
\end{tabular}


way to explore value-added applications based on lignin.

\section{Acknowledgements}

The authors gratefully acknowledge National Natural Science Foundation of China (U1134005/L04) for financial supports.

\section{References}

[1] Gosselink R. J. A., Abächerli A., Semke H., Malherbe R., Käuper P., Nadif A., van Dam J. E. G.: Analytical protocols for characterisation of sulphur-free lignin. Industrial Crops and Products, 19, 271-281 (2004). DOI: $10.1016 /$ j.indcrop.2003.10.008

[2] Saito K., Kato T., Tsuji Y., Fukushima K.: Identifying the characteristic secondary ions of lignin polymer using ToF-SIMS. Biomacromolecules, 6, 678-683 (2005).

DOI: $10.1021 / \mathrm{bm} 049521 \mathrm{v}$

[3] Lora J. H., Glasser W. G.: Recent industrial applications of lignin: A sustainable alternative to nonrenewable materials. Journal of Polymers and the Environment, 10, 39-48 (2002).

DOI: 10.1023/A:1021070006895

[4] Stewart D.: Lignin as a base material for materials applications: Chemistry, application and economics. Industrial Crops and Products, 27, 202-207 (2008). DOI: $10.1016 /$ j.indcrop.2007.07.008

[5] Pouteau C., Dole P., Cathala B., Averous L., Boquillon N.: Antioxidant properties of lignin in polypropylene. Polymer Degradation and Stability, 81, 9-18 (2003). DOI: 10.1016/S0141-3910(03)00057-0

[6] Hambardzumyan A., Foulon L., Chabbert B., AguiéBéghin V.: Natural organic UV-absorbent coatings based on cellulose and lignin: Designed effects on spectroscopic properties. Biomacromolecules, 13, 4081-4088 (2012). DOI: $10.1021 / \mathrm{bm} 301373 \mathrm{~b}$

[7] Lalwani G., Henslee A. M., Farshid B., Lin L., Kasper F. K., Qin Y-X., Mikos A. G., Sitharaman B.: Twodimensional nanostructure-reinforced biodegradable polymeric nanocomposites for bone tissue engineering. Biomacromolecules, 14, 900-909 (2013). DOI: $10.1021 / \mathrm{bm} 301995 \mathrm{~s}$

[8] Aricò A. S., Bruce P., Scrosati B., Tarascon J-M., van Schalkwijk W.: Nanostructured materials for advanced energy conversion and storage devices. Nature Materials, 4, 366-377 (2005).

DOI: $10.1038 /$ nmat 1368

[9] Walsh M. J., Yoshida K., Kuwabara A., Pay M. L., Gai P. L., Boyes E. D.: On the structural origin of the catalytic properties of inherently strained ultrasmall decahedral gold nanoparticles. Nano Letters, 12, 2027-2031 (2012). DOI: $10.1021 / \mathrm{nl} 300067 \mathrm{q}$
[10] Shamsipur M., Asgari M., Mousavi M. F., Davarkhah R.: A novel hydrogen peroxide sensor based on the direct electron transfer of catalase immobilized on nano-sized NiO/MWCNTs composite film. Electroanalysis, 24, 357-367 (2012).

DOI: $10.1002 /$ elan.201100453

[11] Panyam J., Labhasetwar V.: Biodegradable nanoparticles for drug and gene delivery to cells and tissue. Advanced Drug Delivery Reviews, 64, 61-71 (2012). DOI: 10.1016/S0169-409X(02)00228-4

[12] Vainio U., Maximova N., Hortling B., Laine J., Stenius P., Simola L. K., Gravitis J., Serimaa R.: Morphology of dry lignins and size and shape of dissolved kraft lignin particles by X-ray scattering. Langmuir, 20, 9736-9744 (2004).

DOI: $10.1021 / 1 \mathrm{a} 048407 \mathrm{v}$

[13] Lindströmn T.: The colloidal behaviour of kraft lignin. Colloid and Polymer Science, 257, 277-285 (1979). DOI: $10.1007 / \mathrm{BF} 01382370$

[14] Kubo S., Kadla J. F.: Hydrogen bonding in lignin: A Fourier transform infrared model compound study. Biomacromolecules, 6, 2815-2821 (2005). DOI: $10.1021 / \mathrm{bm} 050288 \mathrm{q}$

[15] Deng Y., Feng X., Zhou M., Qian Y., Yu H., Qiu X.: Investigation of aggregation and assembly of alkali lignin using iodine as a probe. Biomacromolecules, 12, 1116-1125 (2011). DOI: $10.1021 / \mathrm{bm} 101449 \mathrm{~b}$

[16] Caicedo H. M., Dempere L. A., Vermerris W.: Template-mediated synthesis and bio-functionalization of flexible lignin-based nanotubes and nanowires. Nanotechnology, 23, 105605/1-105605/12 (2012). DOI: $10.1088 / 0957-4484 / 23 / 10 / 105605$

[17] Spender J., Demers A. L., Xie X., Cline A. E., Earle M. A., Ellis L. D., Neivandt D. J.: Method for production of polymer and carbon nanofibers from water-soluble polymers. Nano Letters, 12, 3857-3860 (2012). DOI: 10.1021/n1301983d

[18] Gonugunta P., Vivekanandhan S., Mohanty A. K., Misra M.: A study on synthesis and characterization of biobased carbon nanoparticles from lignin. World Journal of Nano Science and Engineering, 2, 148-153 (2012). DOI: 10.4236/wjnse.2012.23019

[19] Frangville C., Rutkevičius M., Richter A. P., Velev O. D., Stoyanov S. D., Paunov V. N.: Fabrication of environmentally biodegradable lignin nanoparticles. ChemPhysChem, 13, 4235-4243 (2012). DOI: $10.1002 / \mathrm{cphc} .201200537$

[20] Lu Q., Zhu M., Zu Y., Liu W., Yang L., Zhang Y., Zhao X., Zhang X., Zhang X., Li W.: Comparative antioxidant activity of nanoscale lignin prepared by a supercritical antisolvent (SAS) process with non-nanoscale lignin. Food Chemistry, 135, 63-67 (2012). DOI: 10.1016/j.foodchem.2012.04.070

[21] Ray S. S., Okamoto M.: Polymer/layered silicate nanocomposites: A review from preparation to processing. Progress in Polymer Science, 28, 1539-1641 (2003). DOI: 10.1016/j.progpolymsci.2003.08.002 
[22] Wicklein B., Darder M., Aranda P., Ruiz-Hitzky E.: Bio-organoclays based on phospholipids as immobilization hosts for biological species. Langmuir, 26, 52175225 (2010). DOI: $10.1021 / 1 \mathrm{a} 9036925$

[23] Radian A., Mishael Y. G.: Characterizing and designing polycation-clay nanocomposites as a basis for imazapyr controlled release formulations. Environmental Science and Technology, 42, 1511-1516 (2008).

DOI: $10.1021 /$ es7023753

[24] Darder M., Colilla M., Ruiz-Hitzky E.: Biopolymerclay nanocomposites based on chitosan intercalated in montmorillonite. Chemistry of Materials, 15, 37743780 (2003).

DOI: $10.1021 / \mathrm{cm} 0343047$

[25] Gilman J. W., Awad W. H., Davis R. D., Shields J., Harris R. H., Davis C., Morgan A. B., Sutto T. E., Callahan J., Trulove P. C., DeLong H. C.: Polymer/layered silicate nanocomposites from thermally stable trialkylimidazolium-treated montmorillonite. Chemistry of Materials, 14, 3776-3785 (2002).

DOI: $10.1021 / \mathrm{cm} 011532 \mathrm{x}$

[26] Podsiadlo P., Kaushik A. K., Arruda E. M., Waas A. M., Shim B. S., Xu J., Nandivada H., Pumplin B. G., Lahann J., Ramamoorthy A., Kotov N. A.: Ultrastrong and stiff layered polymer nanocomposites. Science, 318, 80-83 (2007). DOI: $10.1126 /$ science. 1143176

[27] Choi J. H., Park Y. W., Park T. H., Song E. H., Lee H. J., Kim H., Shin S. J., Fai V. L. C., Ju B.: Fuzzy nanoassembly of polyelectrolyte and layered clay multicomposite toward a reliable gas barrier. Langmuir, 28, 6826-6831 (2012).

DOI: $10.1021 / 1 \mathrm{a} 300831 \mathrm{p}$

[28] Joly S., Garnaud G., Ollitrault R., Bokobza L., Mark J. E.: Organically modified layered silicates as reinforcing fillers for natural rubber. Chemistry of Materials, 14, 4202-4208 (2002). DOI: $10.1021 / \mathrm{cm} 020093 \mathrm{e}$

[29] Rooj S., Das A., Stöckelhuber K. W., Reuter U., Heinrich G.: Highly exfoliated natural rubber/clay composites by 'propping-open procedure': The influence of fatty-acid chain length on exfoliation. Macromolecular Materials And Engineering, 297, 369-383 (2012). DOI: 10.1002/mame.201100185

[30] Goring D. A. I., Vuong R., Gancet C., Chanzy H.: The flatness of lignosulfonate macromolecules as demonstrated by electron microscopy. Journal of Applied Polymer Science, 24, 931-936 (1979).

DOI: 10.1002/app.1979.070240406

[31] Jiang C., He H., Jiang H., Ma L., Jia D. M.: Nanolignin filled natural rubber composites: Preparation and characterization. Express Polymer Letters, 7, 480493 (2013).

DOI: $10.3144 /$ expresspolymlett.2013.44
[32] Pulkkinen E., Mäkelä A., Mikkonen H.: Preparation and testing of cationic flocculants from kraft lignin. ACS Symposium Series, 397, 284-293 (1989). DOI: 10.1021/bk-1989-0397.ch021

[33] Laszlo J. A.: Solubility and dye-binding properties of quaternized and peroxidase-polymerized kraft lignin. Environmental Technology, 20, 607-615 (1999). DOI: $10.1080 / 09593332008616855$

[34] Ueno K., Kina K.: Colloid titration-A rapid method for the determination of charged colloid. Journal of Chemical Education, 62, 627-629 (1985). DOI: $10.1021 /$ ed062p627

[35] Breen C.: The characterisation and use of polycationexchanged bentonites. Applied Clay Science, 15, 187219 (1999). DOI: 10.1016/S0169-1317(99)00024-1

[36] Moreva Y. L., Alekseeva N. S., Chernoberezhskii Y. M.: Influence of $\mathrm{NaOH}, \mathrm{HCl}, \mathrm{NaCl}$, and $\mathrm{CaCl}_{2}$ electrolytes on aggregation stability of aqueous craft lignin dispersion according to data of filtration through track membranes. Colloid Journal, 73, 363-367 (2011). DOI: 10.1134/S1061933X11030082

[37] Giles C. H., MacEwan T. H., Nakhwa S. N., Smith D.: Studies in adsorption. Part XI. A system of classification of solution adsorption isotherms, and its use in diagnosis of adsorption mechanisms and in measurement of specific surface areas of solids. Journal of the Chemical Society, 1960, 3973-3993 (1960). DOI: 10.1039/JR9600003973

[38] Miller R., Fainerman V. B., Möhwald H.: Adsorption behavior of oxyethylated surfactants at the air/water interface. Journal of Colloid and Interface Science, 247, 193-199 (2002).

DOI: $10.1006 /$ jcis.2001.8120

[39] Theng B. K. G.: Clay-polymer interactions: Summary and perspectives. Clays and Clay Minerals, 30, 1-10 (1982).

DOI: 10.1346/CCMN.1982.0300101

[40] Beall G. W., Goss M.: Self-assembly of organic molecules on montmorillonite. Applied Clay Science, 27, 179-186 (2004).

DOI: 10.1016/j.clay.2004.06.006

[41] Dang Q., Lu S., Yu S., Sun P., Yuan Z.: Silk fibroin/ montmorillonite nanocomposites: Effect of ph on the conformational transition and clay dispersion. Biomacromolecules, 11, 1796-1801 (2010).

DOI: $\underline{10.1021 / \mathrm{bm} 1002398}$

[42] Pillai K. V., Renneckar S.: Cation- $\pi$ interactions as a mechanism in technical lignin adsorption to cationic surfaces. Biomacromolecules, 10, 798-804 (2009). DOI: $10.1021 / \mathrm{bm} 801284 \mathrm{y}$

[43] Adame D., Beall G. W.: Direct measurement of the constrained polymer region in polyamide/clay nanocomposites and the implications for gas diffusion. Applied Clay Science, 42, 545-552 (2009). DOI: $10.1016 /$ j.clay.2008.03.005 
[44] Davidson M. J. G., Wunder R. H.: Latex coagulation process using lignin compound. U.S. Patent 4025711, USA (1977).

[45] Sirianni A. F.: Puddington I. E.: Laundered amorphous reinforcing lignin. U.S. Patent 3817974, USA (1974).

[46] Harton S. E., Kumar S. K., Yang H., Koga T., Hicks K., Lee H., Mijovic J., Liu M., Vallery R. S., Gidley D. W.: Immobilized polymer layers on spherical nanoparticles. Macromolecules, 43, 3415-3421 (2010). DOI: $10.1021 / \mathrm{ma902484d}$

[47] Lee K. J., Lee D. K., Kim Y. W., Choe W., Kim J. H.: Theoretical consideration on the glass transition behavior of polymer nanocomposites. Journal of Polymer Science Part B: Polymer Physics, 45, 2232-2238 (2007). DOI: $10.1002 /$ polb.21178
[48] Ash B. J., Siegel R. W., Schadler L. S.: Glass-transition temperature behavior of alumina/PMMA nanocomposites. Journal of Polymer Science Part B: Polymer Physics, 42, 4371-4383 (2004).

DOI: $10.1002 /$ polb.20297

[49] Košíková B., Gregorová A.: Sulfur-free lignin as reinforcing component of styrene-butadiene rubber. Journal of Applied Polymer Science, 97, 924-929 (2005). DOI: $10.1002 /$ app. 21448 